Original Contribution

\title{
EFFECT OF PHOTOPERIOD ON HATCHING SUCCESS OF EGGS AND EARLY FRY PERFORMANCE OF CLARIAS GARIEPINUS (SILURIFORMES, BURCHELL 1822)
}

\author{
G. A. Ataguba, V. T. Okomoda*, V. T. Azave \\ Department of Fisheries and Aquaculture, University of Agriculture, Makurdi, Nigeria
}

\begin{abstract}
The present study investigated the effect of egg exposure to three light and dark regimes: 00D: 24L; 24D: 24L; and 12D: 12L on hatching and early growth of Clarias gariepinus larvae. Incubation was carried out in 30L black cylindrical plastic bowls. Hatching rates were determined 24hours post incubation while growth and survival were determined every three days for two weeks. Results obtained reveal no significant difference $(\mathrm{P}>0.05)$ in fertilization rate of eggs assigned to various photoperiods and no effect of photoperiod on mean final weight, mean weight gain, and specific growth rate of fry. However hatching rate and survival rate were significantly affected by light regime $(\mathrm{P}<0.05)$ with fry raised under the light regimes of 12L: 12D and 24L: 00D having significantly higher hatching (84\%) and survival $(54 \%)$ rates. A favorable temperature as well as better vision in search and capture of food aided fish under these treatments to perform better. Photoperiod can therefore be used to enhance incubation, hatching and early growth of $C$. gariepinus with potential to maximize hatching from egg batches.
\end{abstract}

Key words: Incubation, growth, light regime, survival rate.

\section{INTRODUCTION}

The widely distributed, air breathing, sharp tooth catfish (Clarias gariepinus) is the commonest species of fish used for intensive culture in Nigeria and third most cultured in Africa. It is omnivorous, grows fast, tolerate poor water quality and methods for its induced spawning and hatching are well developed (1). One of the constraints to successful culture of larval Clarias gariepinus is the high rate of mortality linked to inadequate larval food, improper feeding regime, stocking density, (2) and photoperiod (3). Photoperiod notably affects feeding activity, but also plays a decisive role in growth, survival and social behaviour (3).

A number of studies have assessed the effect of photoperiod on fingerlings, juvenile or semiadult stage of the African catfish (3, 4). However studies on photoperiod effect on eggs and larvae/fry of tropical fish species are very scarce and to our knowledge this study

\footnotetext{
*Correspondence to: $O K O M O D A, V . T$., Department of Fisheries and Aquaculture, University of Agriculture, Makurdi, Nigeria, Tel: +2348033319959, e-mail:

okomodavictor@yahoo.com
}

represent the first account of photoperiod effect on hatching of the eggs of $C$. gariepinus. Photoperiod requirements are species specific and may vary according to the ontogenetic developmental stage (5), the positive effects on the growth and/or survival can occur under continuous light, intermediary photoperiods, or continuous darkness (6). Incubation of spotted rose snapper, (Lutjanus guttatus) eggs under continuous light has been found to increase the incubation period of some groups of eggs and subsequently affecting entire treatments (7) with implications for management time and cost. This study is designed to determine if exposure to light or darkness can elicit communal behavior in hatching of $C$. gariepinus eggs hence development of management practices which will further enhance the production of African catfish fry.

\section{MATERIALS AND METHODS}

Broodstock of Clarias gariepinus were obtained from the University of Agriculture Makurdi, Aquaculture Research farm and acclimatized at a detached hatchery within the same institution. Broodstock were fed to satiation with a $35 \%$ crude protein pelleted diet twice daily. Six (6) black plastic bowls of 30 liters were assigned to three photoperiods 
namely; twenty-four hours of light (00D: 24L), twelve hours of light, twelve hours of darkness (12D: 12L) and twenty-four hours of darkness (24D: 00L). The light phase was achieved with the aid of energy bulbs emitting 150 lux intensity of light continually powered by electricity. The top of the bowls were covered with boards wrapped with black PVC material to ensure integrity of the desired photoperiod. Openings were made on one side of the bowls and PVC pipes connected to allow aerator into the incubation medium for easy aeration.

Broodstock were injected with Ovaprim ${ }^{\circledR}$ at a dosage of $0.5 \mathrm{ml} \cdot \mathrm{kg}^{-1}$ body weight to induce ovulation; this was carried out via intramuscular injection without anesthetic. After a latency period of twelve hours, the eggs were collected into a clean bowl by gently pressing the abdomen of the fish. Milt was obtained by sacrificing the males, removing the testes; cutting laterally and squeezing it unto the egg mass fertilize the eggs. After a gentle and thorough stir, the eggs were transferred and incubated in plastic bowls prepared according to the different photoperiods. Hatching was considered complete after $28 \mathrm{~h}$ post-fertilization, and the hatching rates were evaluated about 32 hours after. Fertilization and Hatching Rate were determined according to the methods described by (8). Three hundred first feeding fry were stocked for each photoperiod and fed shell free artemia while growth parameters were observed for two weeks. Fish were bulk weighed using a sensitive weighing balance every three days and mean weights were obtained after counting.

Growth parameters were determined as follows

- Final mean weight (mg);

- Weight gain,: $\mathrm{W}_{1}-\mathrm{W}_{0}(\mathrm{mg})$;

- Growth rate, : $\frac{W_{1}-W_{0}}{t}$ and

- Specific growth rate (SGR): $100 \times \frac{\operatorname{Ln} W_{1}-\operatorname{Ln} W_{0}}{t}$

Data collected were analyzed using Genstat Discovery 3 edition. Fertilization, Hatching rates survival and other growth parameters were compared using one-way ANOVA followed by Fisher's LSD to determine significant differences among means

\section{RESULTS AND DISCUSSION}

The study observed that fertilization rate of eggs exposed to the different photoperiod did not differ significantly $(\mathrm{P}>0.05)$ among the photoperiods; since egg from the different broodstock were collected in the same bowl and thoroughly stirred with the milt during fertilization, differences observed in the parameters measured where not in any form due to spawning differences but to the photoperiods applied. Eggs incubated at normal day light duration (equinox) and prolonged light hours (12L: $12 \mathrm{D}$ and 24L: 00D) have the highest hatching rate $(85.14 \%$ and $83.65 \%$ respectively) at the end of 24 hours compared to 24D: 00L which had the least hatching rate $(69.47 \%)$. This observed difference (Table 1) may be due to temperature difference that was higher in lighted incubation chamber (Table 2) compared to those incubated in darkness. Energy saving bulbs were used in the present study (to minimize temperature rise induced by lighting source), however, continuous exposure to static enclosed (Black) surface of water possibly caused temperature rise which in turn influenced hatching rate, hence the result of this study differs from the findings of (9) who reported no significant difference in eggs hatched under different photoperiod in a recirculatory aquaculture system. More so, the age and prolonged exposure of brood fish used in his report may have constituted a source of variance. Hatching rate in the present study was therefore higher than $35-44.4 \%$ range reported by (9).

Growth parameters recorded in this study were not statistically different $(\mathrm{P}>0.05)$ between the three photoperiods. However, (10) reported that permanent darkness enhances the growth of Clarias gariepinus larvae during and after metamorphosis. This difference may be attributed to differences in the time of exposure and diets used. Larvae of western Atlantic seabream Archosargus rhomboidalis (L.), (11) have higher growth rate when cultivated at intermediary or shorter photoperiods. However, growth of larvae of Acanthopagrus schlegelii and S. senegalensis was similar to that of larvae reared at an intermediary photoperiod or under constant illumination (12). (13) observed that first feeding Arctic char Salvelinus alpinus subjected to 24 hours of continuous light and continuous feeding had a higher final weight compared to fish raised in either ambient photoperiods or under restricted feeding 
regimes, hence photoperiod effect differ with species.

Survival in the present study was significantly higher $(\mathrm{P}<0.05)$ in fry raised in $24 \mathrm{~L}$ : $00 \mathrm{D}$ $(54.85 \%)$ and $12 \mathrm{~L}: 12 \mathrm{D}(53.55 \%)$ while $24 \mathrm{D}$ : 00L had the least Survival rate $(47.10 \%)$. Previous studies have associated mortalities in larvae and juvenile stage to cannibalism and it is estimated to contribute up to $70-83 \%$ of the total mortality accumulated during the first 4650 days of rearing C. gariepinus (14). Several studies have also shown that cannibalistic behaviour is intensified by increasing size heterogeneity at these stages; size variation is also a primary cause of agonistic behaviour, which in turn can have the same end effect as cannibalism (15). However with the result of homogeneity reported in the present study for growth, cannibalism is likely not the cause of mortality in the present study but may be linked to accessibility to food (14) had pointed out that high rate of mortality of African catfish is linked to inadequate larval food, improper feeding regime, stocking density and photoperiod (16) and (17) rightly stated that light and dark alternation generally are the
ATAGUBA G. A., et al. main synchronizer of feeding activity, this is likely true for the developmental stage under study. Vision (assisted by extended lighting hours) at this stage is paramount for finding and capture of food, hence mortality as a result of starvation are more in dark incubation tanks compared to those with continuous or regulated light. However as the fish grows bigger with increased feeding affinity, antagonistic behaviour as well as cannibalism will set in, hence this result differ from reported work on fingerlings and juvenile of African catfish as reported by (3) and (4) hence, confirming the hypothesis of (5) that photoperiod response differ for different developmental stages of a fish.

The present study has demonstrated the likelihood of better hatching performance using extended periods of light. However, since earlier reports have demonstrated better growth of the African Catfish in dark media further research should be performed to better understand the timing/ideal switch-period between photoperiod that will enhance the productivity of this important tropical fish.

Table 1. Growth performance of C. gariepinus fry reared under different photoperiods

\begin{tabular}{lllll}
\hline Photoperiod & 12L:12D (TR1) & $\begin{array}{l}\text { 24D:00L } \\
\text { (TR2) }\end{array}$ & 24L:00D (TR3) & P>0.05 \\
\hline Fertilization & $84.18 \pm 0.93$ & $83.99 \pm 2.47$ & $84.03 \pm 1.63$ & 0.997 \\
Hatching rate & $85.14 \pm 4.48^{\mathrm{a}}$ & $69.47 \pm 2.24^{\mathrm{b}}$ & $83.65 \pm 2.99^{\mathrm{a}}$ & 0.05 \\
MIW (mg) & $12.0 \pm 1.0$ & $12.5 \pm 1.5$ & $13.0 \pm 1.0$ & 0.846 \\
MFW (mg) & $22.5 \pm 1.5$ & $21.5 \pm 0.5$ & $21.5 \pm 1.5$ & 0.821 \\
SGR & $10.49 \pm 0.28$ & $9.16 \pm 1.62$ & $8.39 \pm 2.45$ & 0.683 \\
Survival & $10.49 \pm 0.28$ & $9.16 \pm 1.62$ & $8.39 \pm 2.45$ & 0.707 \\
\hline
\end{tabular}

Means in the same column with different superscripts differ significantly $(\mathrm{P}<0.05)$

MIW = Mean Initial Weight

MFW = Mean Final Weight

MWG = Mean Weight Gain

$\mathrm{SGR}=$ Specific Growth Rate

Table 2. Physico-chemical parameters of water from the different photoperiods

\begin{tabular}{lllll}
\hline Photoperiod & 12L:12D (TR1) & $\begin{array}{l}\text { 24D:00L } \\
\text { (TR2) }\end{array}$ & 24L:00D (TR3) & P>0.05 \\
& & & \\
\hline DO & $5.8 \pm 0.34$ & $5.2 \pm 1.21$ & $5.5 \pm 0.21$ & 0.497 \\
pH & $6.7 \pm 0.44$ & $7.0 \pm 0.25$ & $7.1 \pm 0.23$ & 0.565 \\
Temperature & $29.5 \pm 0.27^{\mathrm{a}}$ & $26.9 \pm 0.81^{\mathrm{b}}$ & $30.2 \pm 2.1^{\mathrm{a}}$ & 0.002 \\
\hline
\end{tabular}

\section{REFERENCES}

1. Segner, H., and Verreth, J. Metabolic enzyme activities in larvae of the African catfish, Clarias gariepinus - changes in relation to age and nutrition. Fish
Physiology and Biochemistry., 14: 385398, 1995.

2. Hecht, T. and Appelbaum, S.. Observations on intraspecific aggression and coeval sibling cannibalism by larval and juvenile Clarias gariepinus (Clariidae: Piscis) under 
controlled conditions. Journal of Zoology London 214: 21-44, 1988

3. Almaza'n Rueda, P.. Towards assessment of welfare in African catfish, Clarias gariepinus: the first step. $\mathrm{PhD}$ dissertation, Wageningen University, Wageningen, The Netherlands. 2004

4. Solomon S.G. and Okomoda V.T.: Growth response and aggressive behaviour of Clarias gariepinus fingerlings reared at different photoperiods in a water recirculatory system. Livestock Research for Rural Development. Volume (24), Article \#191. Retrieved November 7, 2012, from http://www.lrrd.org/lrrd24/11/shol24191.ht $\mathrm{m}, 2012$

5. Kestemont, P., jourdan, S., Houbart, M ., Melard, C., Paspatis, M ., Fontainne, P., Cuvier, A., Kentouri, M., andBaras, E.,. Size heterogeneity, cannibalism and competition in cultured predatory fish larvae: biotic and abiotic influences. Aquaculture 227: 333-356, 2003

6. Baldisserotto, B: Fisiologia de peixes aplicadaà piscicultura.Santa Maria: Editora UFSM. 2002.

7. Duncan, N.J, Ibarra-Castro, L. and AlvarezVillasenior, R. . Effect of the dusk photoperiod change from light todark on the incubation period of eggs of the spottedrose snapper,Lutjanus guttatus(Steindachner). Aquaculture Research, 39: 427 - 433, 2008

8. Ataguba, G.A, Annune, P.A. and Ogbe, F.G.: Induced breeding and early growth of progeny from crosses between two African clarrid fishes, Clarias gariepinus (Burchell) and Heterobranchus longifilis under hatchery conditions. Journal of Applied Biosciences 14: 755-760, 2009.

9. Al-khamees S. A. Photoperiod effects on circadian rhythms and puberty onset in African catfish Clarias gariepinus, Ph.D thesis Institute of Aquaculture, University
ATAGUBA G. A., et al. of Stirling, Stirling, Scotland, UK. Pp 276, 2009.

10.Appelbaum, S. and McGeer, J. C..Effect of diet and light regime on growth and survival of African catfish (Clarias gariepinus) larvae and early juveniles. Aquaculture Nutrition 4: 157-164, 1998.

11.Fielder, D.S, Bardsley, W.J, Allan, G.L. and Pankhurst, P.M. Effect of photoperiod on growth and survival of snapper Pagrus auratus larvae. Aquaculture 211: 135 150, 2002.

12.Canavate J.P., Zerolo R. and FernaLndez$\mathrm{D} \mid$.az C. Feeding and development of Senegal sole (Solea senegalensis) larvae reared in different photoperiods. Aquaculture 258: 368-377, 2006

13.Burke M. G., Kirk M. R. Macbeth., N. A, Bevan D. J., and R. D. Moccia; Influence of Photoperiod and Feed Delivery on Growth and Survival of First-Feeding Arctic Char. North American Journal of Aquaculture 67:344-350, 2005

14.Hecht, T. and Appelbaum, S. Notes on the growth of Israeli sharptooth catfish (Clarias gariepinus) during the primary nursing phase. Aquaculture, 63: 195-204, 1987

15.Hseu, J.R.. Effects of size difference and stocking density on cannibalism rate of juvenile grouper, Epinephelus coioides. Fisheries Science 68: 1384-1386, 2002.

16.Boujard, T., Moreau, Y. and Luquet, P.. Entrainment of the circadian rhythm of food demand by infradian cycles of light-dark alternation in Hoplosternum littorale (Teleostei). Aquatic Living Resources 4: 221-225, 1991.

17.Hossain, M. A. R., Beveridge, M. C. M. and Haylor, G. S.. The effects of density, light and shelter on the growth and survival of African catfish (Clarias gariepinus Burchell, 1822) fingerlings. Aquaculture 160: 251-258, 1998. 